\title{
EFEITOS DO PRÉ-TRATAMENTO COM PEPTÍDEO NATRIURÉTICO TIPO C NA MATURAÇÃO DE OÓCITOS BOVINOS - UMA REVISÃO
}

\author{
Israel Levi Nascimento Silva'; Ana Normélia Pereira de Morais²; Valdevane Rocha Araújo ${ }^{3}$ \\ ${ }^{1}$ Graduando, Universidade Estadual do Ceará (UECE), Fortaleza, Ceará, ${ }^{2}$ Mestra, Universidade \\ Estadual do Ceará (UECE), Fortaleza, Ceará, ${ }^{3}$ Doutora, Universidade Estadual do Ceará (UECE), \\ Fortaleza, Ceará.
}

DOI: 10.47094/ICONNECA.2021/8

\begin{abstract}
RESUMO
Esta revisão de literatura teve como objetivo relatar e analisar os efeitos positivos da implantação de um sistema de pré-maturação in vitro (pré-MIV) adicionado de peptídeo natriurético do tipo C (PNC) em oócitos bovinos. Para coleta de dados foram utilizados os bancos de dados PubMed, LILACS e ScienceDirect, dentre os quais 7 artigos foram selecionados e avaliados de acordo com os objetivos do estudo. Os resultados demonstraram que a aplicação do sistema de pré-MIV com PNC aumenta significativamente o número de oócitos parados na divisão meiótica, aumenta os níveis de segundos mensageiros no oócito, favorece a abertura de junções GAP e a manutenção das projeções transzonais dos complexos cumulus-oócitos. Além disso, os artigos apresentaram resultados que revelam a efetividade do tratamento de pré-maturação com PNC no desenvolvimento embrionário. Assim, o sistema de pré-MIV com adição de PNC tem potencial para aumentar a eficácia da biotécnica de MIV em oócitos bovinos.
\end{abstract}

PALAVRAS-CHAVES: Biotécnica reprodutiva. Pré-maturação. Gado.

ÁREA TEMÁTICA: Reprodução animal.

\section{INTRODUÇÃO}

A maturação in vitro oocitária (MIV) compreende o crescimento e a competência do gameta feminino, sendo uma importante fase para subsequente produção in vitro de embriões e maiores taxas de reprodução no rebanho, garantindo obtenção de animais com alto valor zootécnico, por exemplo. Entretanto, a remoção do oócito do ambiente ovariano desencadeia a saída prematura deste do estágio de vesícula germinativa (VG) (FRANCIOSI et al., 2014). Esta, por sua vez, diz respeito a retomada da meiose de forma precoce no oócito, prejudicando a coordenação entre o desenvolvimento e o processo de maturação nuclear da célula reprodutiva. Por esta razão, a implementação de sistemas de cultivo com pré-maturação do complexo cumulus-oócito (CCO) com adição de substâncias que retardam a saída do estágio de VG tem sido utilizada para contornar esse impasse. Dentre estas substâncias, destaca-se o peptídeo natriurético do tipo C (PNC), um regulador parácrino sintetizado 
no ovário pelas células da granulosa. Este peptídeo ativa seus receptores presentes nos CCOs, que sinalizam a produção do segundo mensageiro monofosfato cíclico de guanosina (GMPc), o qual adentra no oócito através da comunicação mediada por junções GAP. Dentro do oócito, a cascata de sinalização gerada por PNC resulta no aumento do segundo mensageiro monofosfato cíclico de adenosina (AMPc), responsável por manter a parada meiótica (JIA \& WANG, 2020). Desta forma, esta revisão de literatura teve por objetivo relatar e analisar os efeitos da suplementação do PNC no sistema de pré-maturação de oócitos bovinos.

\section{METODOLOGIA}

Para compor este estudo de revisão foram utilizados os descritores peptídeo natriurético tipo $\mathrm{C}$, maturação in vitro e gado para pesquisa dos artigos por meio dos bancos de dados PubMed, ScienceDirect e Literatura Latino-Americana e do Caribe em Ciências da Saúde (LILACS). Na plataforma PubMed foram encontrados 11 artigos dos quais 7 foram selecionados, nos demais bancos de dados não se obteve resultados (LILACS) ou os artigos já haviam sido selecionados (ScienceDirect). Os critérios de inclusão compreenderam artigos científicos sobre MIV em oócitos bovinos que incluíssem metodologia de pré-tratamento do meio de cultivo, sem haver restrição de período da publicação ou idioma. Os critérios de exclusão limitaram os estudos que não utilizavam do peptídeo natriurético do tipo $\mathrm{C}$ e não tinham como enfoque os efeitos da substância na maturação de oócitos bovinos. Posteriormente, os artigos escolhidos foram analisados e estando de acordo com a proposta do trabalho tiveram seus resultados mais significativos separados e fichados de acordo com cada estudo.

\section{FUNDAMENTAÇÃO TEÓRICA}

Foi demonstrado que a aplicação de um sistema de pré-maturação suplementado com peptídeo natriurético tipo $\mathrm{C}(100 \mathrm{nM})$ por $6 \mathrm{~h}$ seguido do cultivo em meio de MIV por $22 \mathrm{~h}$, foram suficientes para se obter parâmetros de maturação comparáveis aos protocolos padrões de MIV, que utilizam o tempo de incubação de $24 \mathrm{~h}$ (FRANCIOSI et al., 2014). A partir disso, outros estudos identificaram que o pré-tratamento de CCOs com PNC (100 ou $200 \mathrm{nM}$ ) resultou em uma proporção significativamente maior de oócitos mantidos no estágio de $\mathrm{VG}$, evidenciando a propriedade do peptídeo de retardar a retomada meiótica do oócito (FRANCIOSI et al., 2014; SOARES et al., 2017; ZHANG et al., 2017; SOTO-HERAS et al., 2019; ZHENWEI e XIANHUA, 2019; JIA e WANG, 2020). Tais resultados podem ser devido ao aumento significativo nos níveis dos segundos mensageiros GMPc e AMPc (JIA e WANG, 2020), manutenção das projeções transzonais dos CCOs (SOTO-HERAS et al., 2019), além da abertura das junções GAP, facilitando a comunicação celular (SOARES et al., 2017). Estes eventos caracterizam a manutenção da parada da divisão celular no oócito. 
Outros fatores importantes para determinar à qualidade oocitária após o pré-tratamento com PNC são a manutenção da função e o desenvolvimento mitocondrial e, subsequente desenvolvimento embrionário. JIA et al. (2021) evidenciaram o aumento significativo na quantidade de mitocôndrias, bem como no potencial de membrana mitocondrial intra-oócito, elevando as proporções de oócitos com distribuição homogênea desta organela, além de menores níveis de espécies reativas de oxigênio. Além disso, as taxas de clivagem e formação de blastocistos, bem como a contagem de blastômeros aumentaram significativamente após pré-maturação com PNC (FRANCIOSI et al.,2014; ZHANG et al., 2017; JIA \& WANG, 2020).

\section{CONSIDERAÇÕES FINAIS}

A aplicação de um sistema de pré-maturação in vitro adicionada com peptídeo natriurético do tipo C seguido de cultivo em meio de MIV demonstrou um aumento na obtenção de CCOs bovinos após a MIV à medida em que os dados obtidos nesta espécie evidenciaram uma maior competência oocitária, permanência do oócito no estado de VG, aumento de fatores intra-oócito importantes ao sucesso da técnica e resultados favoráveis ao desenvolvimento embrionário.

\section{PRINCIPAIS REFERENCIAS}

FRANCIOSI, Federica et al. Natriuretic Peptide Precursor C Delays Meiotic Resumption and Sustains Gap Junction-Mediated Communication in Bovine Cumulus-Enclosed Oocytes1. Biology Of Reproduction, [S.L.], v. 91, n. 3, p. 1-9, 1 set. 2014.

JIA, Zhenwei; YANG, Xinyu; LIU, Kai. Treatment of cattle oocytes with C-type natriuretic peptide before in vitro maturation enhances oocyte mitochondrial function. Anim Reprod Sci, Tongliao, v. 225, n. 106685, fev. 2021.

JIA, Zhenwei; WANG, Xueli. Effects of C-type natriuretic peptide on meiotic arrest and developmental competence of bovine oocyte derived from small and medium follicles. Scientifc Reports, Tongliao, v. 10 , n. 1 , out. 2020 .

SOARES, Ana Caroline S. et al. Steroid hormones interact with natriuretc peptde C to delay nuclear maturaton, to maintain oocyte-cumulus communicaton and to improve the quality of in vitroproduced. Reproducton, Fertlity And Development, Sao Paulo, v. 29, n. 11, p. 2217-2224, out. 2017.

SOTO-HERAS, Sandra; PARAMIO, Maria-Teresa; THOMPSON, Jeremy G.. Effect of pre-maturation with C-type natriuretic peptide and 3- isobutyl-1-methylxanthine on cumulus-oocyte communication and oocyte developmental competence in cattle. Animal Reproduction Science, Barcelona, v. 202, p. 49-57, jan. 2019.

ZHANG, Tong et al. Effect of C-type natriuretic peptide pretreatment on in vitro bovine oocyte 
maturation. In Vitro Cell Dev Biol Anim, [S.I.], v. 53, n. 3, p. 199-206, mar. 2017.

ZHENWEI, J; XIANHUA, Z. Pre-IVM treatment with C-type natriuretic peptide in the presence of cysteamine enhances bovine oocytes antioxidant defense ability and developmental competence in vitro. Iranian Journal Of Veterinary Research, Tongliao, v. 20, n. 3, p. 173-179, jan. 2019. 